\title{
The Impact of Translation Software on Improving the Performance of Translation Majors
}

\author{
A Case Study of the Saudi Universities
}

\author{
Abdulfattah Omar $^{1 *}$, Ayman F. Khafaga ${ }^{2}$, Iman El-Nabawi Abdel Wahed Shaalan ${ }^{3}$ \\ Department of English, College of Sciences and Humanities, Prince Sattam Bin Abdulaziz University ${ }^{1,2,3}$ \\ Faculty of Arts and Humanities, Suez Canal University, Egypt ${ }^{2}$ \\ College of Humanities, Al-Azhar University, Egypt ${ }^{3}$
}

\begin{abstract}
The recent years have witnessed a high demand for professional translation services due to the global nature of world economy, accessibility to data in different languages, and the development of unprecedented communication channels. Translators can no longer meet these growing needs of customers and businesses. As such, different translation technologies have been developed to help translation learners and professionals improve their performance in producing a high quality translation. These technologies are now widely integrated into translation programs in different universities, institutes and training centers around the world for their usefulness and reliability in improving the performance of translation learners and professionals in the delivery of trustworthy and professional translation services. Nevertheless, surveys show that the Saudi labor market still has serious problems with qualified translators who are familiar with translation technologies that have negative impacts on the quality and delivery of translation services. This study, therefore, seeks to explore the opportunities and challenges of incorporating translation software and latest technologies into translation pedagogy in the Saudi universities. An open-ended interview with 37 translation instructors from 9 Saudi universities was conducted. Results indicate that the integration of translation software and technologies is still less than expected. This can be attributed to the fact that the majority of instructors prefer manual translation over computer-assisted translation (CAT), translation technologies are not provided by the institutions, and learning outcomes are not linked to labor market needs.
\end{abstract}

Keywords-CAT; Saudi Universities; SDL Trados Studios; translation pedagogy; translation technologies

\section{INTRODUCTION}

The applications of technologies to translation studies have always been the core concern of translation professionals and software developers because of the increasing demands for translation services [1-3]. This is due to the very clear fact that nowadays conventional methods of translation no longer satisfy the needs of translation users all over the world, particularly if we consider the unparalleled availability and easy accessibility to data and information in different languages $[2,4,5]$.

Based on the assumption that there are new demands in the field of translation, and attempting to fulfill this gap, different technological tools have been introduced to the field of translation, with the intention to offer new systems that

Paper Submission Date: March 18, 2020

Acceptance Notification Date: April, 13, 2020

*Corresponding Author intended for enhancing the process of translation, both in quality and delivery [3]. Among these new systems are: SYSTRAN, Memsource, SDL Trados Studios, and CSOFT. Other technological applications have also been presented to the field and intended to improve the process of translation and to offer solutions to the different problems that may encounter translators. These include Google Translate, Microsoft and Facebook. Crucially, these applications tend to provide translation services in an easy way and help users to easily connect and communicate with other users [5].

Regardless of the huge development and advancement in software technology in education in general, and in translation in particular, many educational institutions still resist the use of translation technologies and software in instruction and learning processes $[6,7]$. This is clearly shown in the insistence of translation instructors who believe that translation does not need the application of such technologies. They attributed their belief to the fact that translators should entirely depend on their background knowledge (i.e. their schemata) when they come to translate any text [8, 9]. Other factors of the undesirable motivation towards new technologies are due to their inability to familiarize themselves with these technologies, the new changes these technologies undergo from time to time, and the unavailability of language technology [10-13].

It is worth mentioning that the rapid development in technology that the world leads today, as well as the different technological applications in the different aspects of life, together with the unprecedented communication among individuals, businesses and institutions pose some sort of hindrance on the ability of conventional translation to be in conformity with the needs of users within such an atmosphere of technology $[14,15]$. In fact, today's translators are more fortunate than their predecessors for the simple reason that they nowadays have technology that save them time, cost and effort. Traditional methods as well as traditional tools of translation are no longer appropriate for dealing with this huge information we have today. There is no need for paper dictionaries in thousands of pages. However, by a single click, today's translators can access and treat a great deal of information. This technological shift has its own influence on the translators' productivity, their professional skills and their motivation towards a more quick and accurate translation. Further, many changes in translation industry have been marked as indicative, and are technologically highlighted as 
useful in translation practices. Translators today need to be familiar with new fields such as software localization, translation of websites and applications, and even video and online games [14].

Based on the premise that translation industry is a complicated process, it follows then that its traditional perspective methods cease to be effective in preparing and qualifying translation learners towards a new dimension of translation industry featured with a highly and ever-changing technological development. The great changes in translation technologies are supposed to be reflected in translation pedagogy and instruction. The hypothesis is that the incorporation of technological methods into the institutional instruction of translation functions not only to improve the translation process both pedagogically and practically, but also to enhance EFL learners' productivity in the field [15-17].

The remainder of this study is organized as follows. Section 2 is a brief survey of the literature on the integration of technology in technology in education in general and translation pedagogy in particular. Section 3 describes the methods and procedures of the study. Section 4 reports the results and findings. Section 5 concludes the study and offers some recommendations for future research.

\section{LITERATURE REVIEW}

Tracing the literature approached the use of technology in learning indicates that the issue has been the focus of numerous studies in different disciplines since the second half of the $20^{\text {th }}$ century. It is almost agreed that the availability of computers and digital devices in the $20^{\text {th }}$ century changed education in many ways [18]. With the availability of computers and the development of communication channels in an unprecedented manner in the closing years of the $20^{\text {th }}$ century, the integration of technology into education has become a popular option on the part of both learners and instructors. It is even argued that the situational, technological and educational perception of integrating technology into learning has drastically changed towards the end of the $20^{\text {th }}$ century and the advent of the $21^{\text {st }}$ century. This is due to the rapid advancement in information technology that dominates the whole world, which in turn leads to an escalating demand for various kinds of software to meet the needs of users, particularly learning software [19]. Obviously, the internet has contributed significantly to change traditional learning patterns even within formal education. Many changes have taken place very rapidly with the development of the Internet to the extent that many courses have been entirely based on technology in the way they are delivered to learners [20].

The recent years have witnessed the development of different technologies for educational and pedagogical purposes. The progress of technological systems has always been reflected principally on teaching foreign languages, particularly English language teaching (ELT) [21]. Many pedagogical practices have been registered as an ultimate result of the information technology revolution which started with the development of Computer-Mediated Communication (CMC) in the second half of the $20^{\text {th }}$ century [17, 22-24]. Through CMC, users have given a variety of opportunities that activate communication to create, participate, and interpret information by virtue of the employment of telecommunication networks that function to assist encoding, transmitting, and decoding messages. Technology is extensively used in almost all learning contexts to develop learners' language skills. It is noticeable that several studies have deliberately highlighted the reciprocal relationship between the success achieved on the part of the student, on one hand, and the initiatives of education institutions to incorporate current technologies into the processes of learning and teaching, on the other. These studies have further stressed the technological advancement achieved in both learning and teaching methods. It is also argued that the nonattendance of blended modes that flexibly absorb the last development in technology and its effect on learning and teaching have resulted in negative implications on teaching and learning processes, which in turn functions to threaten national competitiveness [25].

In translation pedagogy, different studies indicate clearly that the integration of translation technologies and software into teaching practices has positive impacts on students' achievement [26-30]. It is even imperative for instructors to adopt new teaching patterns and encourage their students to use translation technologies $[31,32]$. In this regard, instructors and academic institutions should be more willing to accept the idea that translation technologies are inevitable in preparing qualified translators and thus should be integrated in one way or another in translation pedagogy [33-35]. This claim is supported by the fact that technology and commitment to deadlines are among the main requirements in the translation industry today $[26,36]$. Educators and program designers thus need to keep their students and learners updated with the industry trends and recent technologies in order to be well qualified for the labor market [37]. In short, translation technology should be central in translation pedagogy and discussions, either in academic institutions or translation companies [38].

Nevertheless, different studies report that the integration of translation technologies into translation pedagogy in universities and higher education institutions is still less than expected. This issue has its negative implications to the global labor market. Sprung and Jaroniec [38] assert that the lack of qualified translators who can apply computer technology to assist in the translation process and meet the demand for translation that is currently rising dramatically is still a major problem. This is largely attributed to the inefficiency of translators and graduates to deal effectively with translation technologies [39]. Very little has been conducted, however, on the attitudes of translation instructors towards the integration of CAT tools and translation software in teaching practices in general and in the Saudi context in particular. This study tends to bridge this gap in literature by exploring the opportunities as well as challenges of incorporating latest translation technology into translation classes in the Saudi universities.

\section{METHODS}

In order to understand the opportunities and challenges of incorporating translation software and latest technologies into translation classrooms, an interview with 37 translation instructors from 7 universities in Saudi Arabia was conducted. The interviews took place during the Academic Year 2018- 
2019. The study targeted the departments and colleges that have translation majors. These include the College of Languages and Translation in King Saud University, College of Languages and Translation and King Abdullah Institute for Translation and Arabization in Al-Imam Mohammad Ibn Saud Islamic University, College of Translation in Princess Nourah Bint Abdul Rahman University, Department of English Language and Translation in Qassim University, and Language and Translation Center in Effat University. These represent the major translation departments and colleges in the Saudi universities. Interviewees were selected from both male and female departments as the Saudi authorities still impose sex segregation policies in education institutions. In order for the data to be representatives, participants were selected on the basis that they represent different groups and that they come from different backgrounds. Respondents' data can be seen in Tables I- VII.

TABLE I. GENDER

\begin{tabular}{|l|l|}
\hline Gender & Number \\
\hline M & 21 \\
\hline F & 16 \\
\hline
\end{tabular}

TABLE II. AGE

\begin{tabular}{|l|l|}
\hline Age & Number \\
\hline $20-30$ & 7 \\
\hline $31-45$ & 17 \\
\hline $45-60$ & 11 \\
\hline $61-$ Above & 2 \\
\hline
\end{tabular}

TABLE III. EDUCATION LEVEL

\begin{tabular}{|l|l|}
\hline Education & Number \\
\hline MA & 9 \\
\hline PhD & 28 \\
\hline
\end{tabular}

TABLE IV. POSITION

\begin{tabular}{|l|l|}
\hline Position & Number \\
\hline Lecturer & 9 \\
\hline Assistant Professor & 24 \\
\hline Associate Professor & 3 \\
\hline Professor & 1 \\
\hline
\end{tabular}

TABLE V. NATIONALITY

\begin{tabular}{|l|l|}
\hline Nationality & Number \\
\hline Egypt & 7 \\
\hline Jordan & 5 \\
\hline Morocco & 1 \\
\hline Saudi Arabia & 18 \\
\hline Sudan & 2 \\
\hline Syria & 1 \\
\hline Tunisia & 2 \\
\hline Yemen & 1 \\
\hline
\end{tabular}

TABLE VI. TEACHING EXPERIENCE

\begin{tabular}{|l|l|}
\hline Translation teaching experience & Number \\
\hline 1-3 Years & 9 \\
\hline 3-5 Years & 14 \\
\hline 5-10 Years & 8 \\
\hline More than 10 Years & 6 \\
\hline
\end{tabular}

TABLE VII. Number of TransLATION COURSES TAUght

\begin{tabular}{|l|l|}
\hline Number of translation courses taught & Number \\
\hline 1 & 10 \\
\hline 2 & 19 \\
\hline 3 & 8 \\
\hline More than 3 & 0 \\
\hline
\end{tabular}

Six open-ended interview questions were asked. These were asked as follows.

a) How can you evaluate translation software and technologies?

b) How useful are CAT tools in translation classrooms?

c) Can you provide examples of translation technologies and list any you have ever used?

d) What are the challenges of integrating CAT tools and translation software into translation classrooms?

e) Can you list the courses that entail the use of CAT tools and translation software in your institution?

f) Describe the relevance of translation courses and the translation program in your institution to labor market needs and requirements.

\section{ANALYSIS AND DisCUSSIONS}

Results indicate that the majority of respondents raised doubts concerning the quality of automatic translations and those based on software and technologies. Many expressed the idea that translation remains a creative task that cannot be achieved by computers and maintained that computers cannot replace translators in anyway. Others referred to the peculiar nature of Arabic and that recent translation systems, either machine translation systems or CAT tools, do not have the potentials of addressing the linguistic peculiarities of Arabic. It was clear also that very few have good background about the available translation software and CAT tools. Many respondents were also confused about machine translation systems and CAT tools.

Very few participants, on the other hand, indicated that the use of translation software can be useful in translation classrooms. They argued that the use of translation technologies would definitely make students more motivated to translate and practice. They also referred to the importance of integrating recent translation technologies into translation classrooms to address the increasing changes within translation processes. Only four instructors, however, indicated that they encouraged their students to use CAT tools and translation software in translation classrooms. They pointed out that they asked their students to use free translation software and CAT tools as they are available and accessible. These instructors 
stressed that the use of CAT tools helped their students to produce professional translations in terms of quality and speed. One instructor reported that they (she) asked their (her) students to install the free-trial version of SDL Trados Studio in the translation of selected legal and medical passages. She postulated clearly that the integration of the translation software into teaching had positive impacts on the students' performance and achievement. Students who used the software were able to provide consistent translations within short periods of time. She also indicated that the use of the software improved students' self-confidence and self-esteem and enhanced their motivation.

The majority of translation instructors do not use computers in their translation classes. However, they asked their students to depend entirely on paper dictionaries rather than using translation websites (Google, Bing). For them, these websites lack reliability in translation. The interviews also demonstrated that there is a general reluctance on the part of translation instructors in terms of using translation technologies, particularly CAT tools. This negative attitude towards translation technologies, as indicated in the results, is due to several reasons: first, translation instructors expressed their agreement that they have never been introduced to any CAT tool, either on the institutional education level or on the personal one. Second, they acknowledged that the educational institutions they are affiliated to do not provide the software for these technological tools. Third, the high costs of these software programs have been shown to be indicative in shaping the general negative attitude concerning the use and application of translation technologies in translation classes. Finally, some referred to the assessment tools. They indicated that assessments are largely based on paper exams where electronic devices and translation software are not allowed for students. In this regard, they believe that there is no argument to use translation technologies as long as they are not part of the assessment process. Significantly, despite their negative attitudes towards the use and application of translation technologies in translation, the majority of the participants showed an anxious interest in learning, using and applying such tools.

Further, the majority of participants also emphasized that there are no courses that require the use of CAT tools in their institutions. Only five participants indicated that they have some courses such Translation Technology and Localization and these are usually taught at graduate levels in Diploma and MA programs. In this regard, they indicated that there is a wide gap between labor market demands and the courses offered in their institutions. Courses are not frequently updated. That is why some participants expressed their disappointment that they have been working with some study plans that have not changed for years.

The responses obtained from the participants clarified that they exhibited a variety of attitudes in terms of using and applying CAT. Some expressed uncertainties, worries, hesitation, and disappointment; others showed anticipation, enthusiasm and excitement. Attempting to find out the reasons beyond these mixed emotions, the interviewed participants revealed some attitudes that revolve around some administrative, personal, educational and financial reasons.
Administratively, the participants were in conformity with the idea that their universities do not provide these technological tools for them. Personally, participants showed lack of confidence in the skills dedicated to using information technology. Educationally, they agreed that they do not use any translation technologies during their translation classes, and that the courses are totally theoretically-based that are oriented towards conventional methods of teaching. Financially, all of them acknowledged that these technologies and their applications software programs are of high cost to afford. These reasons constitute the general attitudinal perception of participants to the use and application of translation technologies in translation classes.

The participants' responses also displayed a complete dependence on traditional and more theoretical methods on the part of translation instructors towards their students in translation classes. As such, students are introduced to merely theoretical topics concerning CAT without any real chance to practice translation by means of using machine translation systems online. Classroom instruction is still conventional and largely depends on print texts, hand writing assignment, and inside classroom discussion through whiteboards. This traditional environment of education allows no chance for computerizing the process of translation. This can be attributed to the fact that the majority of instructors prefer manual translation over computer-assisted translation (CAT), translation technologies are not provided by the institutions, and learning outcomes are not linked to labor market needs. Instructors are urged to integrate translation technologies into their classrooms and adopt new teaching styles and patterns that address the changing needs of the translation industry.

Based on the above results, modern technology, particularly in translation, is expected to expand the general understanding of learners towards the necessity of using and applying technological tools into the process of translation. This in turn functions to produce more efficient and authentic type of translation that can meet the requirements of labor market today [40]. Obviously, pursuing the applications of these technological advancements requires continuous, frequent and steady updates to the different programs of translation software in a way that guarantees better performance and a high quality of productivity. This, of course, does not mean to neglect the part played by translators, i.e. the humankind source, since there are so many problems encounter translators that necessitate the traditional human intervention, such as the problems of translating culture-specific idioms, translation of metaphor and allegorical language the translation of religious-oriented expressions, as well as any type of translation that targets the very particular aspects of a specific culture that needs a translator who is comprehensibly able to understand the linguistic, cultural and social features inherited in the source language linguistic and cultural systems. [41-43]. As such, one cannot proclaim that translation technologies can affect the human role; each has a dedicated role that should be incorporated for more efficient, more accurate and more credible translation Modern technologies in translation represent no threat at all for translators; however, they are tools that facilitate the process of translation $[44,45]$. 
Finally, Saudi academic institutions should envision translation as a product that needs to be recurrently developed and enhanced by keeping an eye on the last developments in the field. This professional view will enable them to prepare a well-qualified generation of translators equipped with the latest technological advancements to meet the ever-changed requirements of translation market. [26]. Crucially, the integration of technology into translation teaching and learning, i.e. to be introduced as an inseparable part of translation pedagogy, creates a link between academic institutions and the local as well as the international market of translation.

\section{CONCLUSION}

This study attempted to explore the extent to which technology is influentially contributive to the process of teaching and/or learning translation. The analysis demonstrated that despite the significant part translation technologies and software programs play on improving the professional standards of translation and EFL students' translation productivity, they are still far from being applied as institutionally authorized parts of translation pedagogy. Without the use of translation technologies, translators cease to operate adequately to offer a high quality translation services. It is analytically evidenced that the use of CAT tools function to facilitate the process of translation, make it more effective and convenient, and help learners to provide an honestly eminent translation in a comparatively fast pace. The application of CAT tools to translation courses, therefore, functions to increase productivity and quality in translation, as well as to produce highly competent translators, who have the ability to meet the needs of today's technologically-shaped market of translation.

As demonstrated from the analysis above, there is an urgent need for the use and application of translation technologies in general, and CAT tools in particular, in translation courses. This, on the one hand, functions to improve learners' skills and to maximize their productivity. Translation instructors, on the other hand, are recommended to provide and integrate further technological tools and meaningful tasks within their classes rather than focusing on merely theoretically-based aspects of translation. In this regard, Saudi Universities are also recommended to provide the required software that guarantees the application of technology to translation courses. Understanding the attitudes of instructors towards the integration of CAT tools and translation software in teaching and learning processes is also important for the successful and effective integration of technology in translation classrooms.

It can be concluded then that CAT tools, machine translation systems, and other translation technologies should be central in translation pedagogy, studies, discussions, and program designs. Translation instructors should be more flexible to the inevitability of translation technologies in translation learning and industry today. In this regard, universities are recommended to make CAT tools and translation technologies accessible to both instructors and students. They should also provide training programs in order to overcome any technical problems or challenges. It is important for universities and educational institutions to reconsider translation. Translation should be seen as a product and an industry. The program outcomes should address the employers' needs and labor market requirements.

For future research, and based on the assumption that translation technologies wholeheartedly galvanize and subsume the translation process, a technologically critical move then is recommended towards the study of the effective use of these technologies, the way they are used to achieve the ideal results, and the pedagogical implications they contribute to the process of learning and teaching. Also recommended is extensive comparative studies on the learning outcomes resulted in the conventional and technological methods applied to translation courses.

\section{ACKNOWLEDGMENT}

We take this opportunity to thank Prince Sattam Bin Abdulaziz University in Saudi Arabia alongside its Deanship of Scientific Research, for all technical support it has unstintingly provided towards the fulfillment of the current research project.

\section{REFERENCES}

[1] C. K. Quah, Translation and Technology. Palgrave Macmillan UK, 2006.

[2] M. O'Hagan, The Routledge Handbook of Translation and Technology. Taylor \& Francis, 2019.

[3] S. Yao, "Application of Computer-aided Translation in English Teaching," International Journal of Emerging Technologies in Learning (iJET), vol. 12, no. 8, pp. 105-117, 2017.

[4] D. Kenny, Human Issues in Translation Technology: The IATIS Yearbook. Taylor \& Francis, 2017.

[5] C. Sin-wai, The Future of Translation Technology: Towards a World without Babel. Taylor \& Francis, 2016.

[6] M. J. Varela, "How New Technologies Improve Translation Pedagogy," Translation Journal, vol. 11, no. 4, 2007.

[7] N. Dwivedi, Exploring Institutional Logics for Technology-Mediated Higher Education. Taylor \& Francis, 2019.

[8] R. Youdale, Using Computers in the Translation of Literary Style: Challenges and Opportunities. Taylor \& Francis, 2019.

[9] H. Somers, Computers and Translation: A translator's guide. John Benjamins Publishing Company, 2003.

[10] M. Al Gamdi and A. Samarji, "Perceived barriers towards e-Learning by faculty members at a recently established university in Saudi Arabia," International Journal of Information and Education Technology, vol. 6, no. 1, p. 23, 2016.

[11] H. Liu, C.-H. Lin, D. Zhang, and B. Zheng, "Language teachers' perceptions of external and internal factors in their instructional (non-) use of technology," in Preparing foreign language teachers for nextgeneration education: IGI Global, 2017, pp. 56-73.

[12] W. Daelemans and V. Hoste, Evaluation of Translation Technology. Artesis Univ. College Antwerp, Department of Translators \& Interpreters, 2010.

[13] M. E. Auer and T. Tsiatsos, The Challenges of the Digital Transformation in Education: Proceedings of the 21st International Conference on Interactive Collaborative Learning (ICL2018) (no. v. 1). Springer International Publishing, 2019.

[14] M. Cronin, Translation and Globalization. Taylor \& Francis, 2013.

[15] F. Yue, Y. Tao, H. Wang, Q. Cui, and B. Xu, Restructuring Translation Education: Implications from China for the Rest of the World. Springer Singapore, 2019.

[16] A. Pym, A. Perekrestenko, and B. Starink, Translation Technology and Its Teaching: (with Much Mention of Localization). Intercultural Studies Group, Universitat Rovira i Virgili, 2006.

[17] W. Gong, "An Innovative English Teaching System Based on Computer Aided Technology and Corpus Management," international Journal of 
Emerging Technologies in Learning (iJET), vol. 14, no. 14, pp. 69-80, 2019.

[18] M. Henderson, M. J. Henderson, and G. Romeo, Teaching and Digital Technologies: Big Issues and Critical Questions. Cambridge University Press, 2015.

[19] R. M. Baecker, Computers and Society: Modern Perspectives. Oxford University Press, 2019.

[20] A. G. Picciano, Online Education: Foundations, Planning, and Pedagogy. Taylor \& Francis, 2018.

[21] S. A. Shariffuddin, W. R. W. Shaaidi, and S. M. Hashim, "Social networks as instructional tools beyond a classroom," International Journal of Advanced and Applied Sciences, vol. 4, no. 12, pp. 185-192, 2017.

[22] F. Farr and L. Murray, The Routledge Handbook of Language Learning and Technology. Taylor \& Francis, 2016.

[23] A. Pareja-Lora, C. Calle-Martínez, and P. Rodríguez-Arancón, New perspectives on teaching and working with languages in the digital era. Research-publishing.net, 2016.

[24] Y. Jin, "Design of Students' Spoken English Pronunciation Training System Based on Computer VB Platform," International Journal of Emerging Technologies in Learning (iJET), vol. 14, no. 6, pp. 41-52, 2019.

[25] M. Muhamad and G. H. Seng, "Teachers' perspective of 21st century learning skills in Malaysian ESL classrooms," international Journal of Advanced and Applied Sciences, vol. 6, no. 10, pp. 32-37, 2019.

[26] F. P. Ramos, "Quality Assurance in Legal Translation: Evaluating Process, Competence and Product in the Pursuit of Adequacy," International Journal for the Semiotics of Law, vol. 28, no. 1, pp. 11-30, 2014.

[27] S.-w. Chan, The Routledge Encyclopedia of Translation Technology. London; New York: Routledge 2014.

[28] L. Bowker, Computer-aided Translation Technology: A Practical Introduction. Ottawa: Ontario: University of Ottawa Press, 2002.

[29] D. Barr, "Embedding technology in translation teaching: evaluative considerations for courseware integration," Computer Assisted Language Learning, vol. 26, no. 4, pp. 295-310, 2013/10/01 2013.

[30] L. Zhang, "Study on the Application of Web Information Retrieval in the Teaching of Language Translation," International Journal of Emerging Technologies in Learning (iJET), vol. 11, no. 4, pp. 14-119, 2016.

[31] M. C. Odacoglu and S. Kokturk, "The effects of technology on translation students in academic translation teaching," presented at the 7th World Conference on Educational Sciences, (WCES-2015), Athens, Greece, 05-07 February 2015, 2015.
[32] D. Chunzhi, "Computer-Aided Translation in Student's Practical Translation Competence," presented at the 3rd International Conference on Science and Social Research, 2014.

[33] C. Liu and C. Yu, "Understanding students' motivation in translation learning: a case study from the self-concept perspective," Asian-Pacific Journal of Second and Foreign Language Education, vol. 4, no. 4, pp. 119, 2019.

[34] H. Salhi, "Translator for Translating in Tunisia Today: Market Challenges and Available Opportunities," Comparative Linguistics, vol. 5, no. 1, pp. 35-49, 2011.

[35] J. Horbačauskienė, R. Kasperavičienè, and S. Petroniene, "Translation studies:Translator training vs employers' expectations " Journal of Language and Cultural Education, vol. 5, no. 1, pp. 145-159, 2017.

[36] D. Gouadec, Translation as a Profession. Amsterdam, Philadelphia: John Benjamins Publishing Company, 2007.

[37] N. N. Shahri, A. H. Fatemi, M. Khoshsaligheh, and Z. B. Farimani, "A Didactic Approach to Curriculum Renewal on the Basis of Market Demands: A Grounded Theory Study," International Journal of Curriculum and Instruction, vol. 8, no. 2, pp. 97-116, 2016.

[38] R. C. Sprung and S. Jaroniec, Translating Into Success: Cutting-edge Strategies for Going Multilingual in a Global Age. John Benjamins, 2000.

[39] A. H. Fatani, "The State of the Translation Industry in Saudi Arabia " Translation Journal, vol. 13, no. 4, 2009.

[40] Z. Erwen and Z. Wenming, "Application of Computer-Aided Translation Technology in Translation Teaching," International Journal of Emerging Technologies in Learning (iJET), vol. 8, no. 5, pp. 15-20, 2013.

[41] E. Shutova, L. Sun, E. D. Gutiérrez, P. Lichtenstein, and S. Narayanan, "Multilingual metaphor processing: Experiments with semi-supervised and unsupervised learning," Computational Linguistics, vol. 43, no. 1, pp. 71-123, 2017.

[42] T. Poibeau, Machine Translation. MA: MIT Press, 2017.

[43] F. Van Eydne, Linguistic Issues in Machine Translation. Bloomsbury Publishing, 2015.

[44] A. M. Abdulmalek, "Artificial intelligence and natural language processing: the Arabic corpora in online translation software," International Journal of Advanced and Applied Sciences, vol. 3, no. 9, pp. 59-66, 2016.

[45] A. A. Q. AlRababah, "On the associative memory utilization in EnglishArabic natural language processing," International Journal of Advanced and Applied Sciences, vol. 4, no. 8, pp. 14-18, 2017. 